\title{
Cognitive Emotion Regulation Strategies and Insomnia or Other Psychiatric Symptoms among Humidifier Disinfectant Victims
}

\author{
Seockhoon Chung, $\mathrm{MD}^{1,2}$, Suk-Hoon Kang, $\mathrm{MD}^{3}$, Kukju Kweon, $\mathrm{MD}^{4}$, Soyoung Youn, $\mathrm{MD}^{1}$, \\ Hyang Soon Kang, RN², Sang-Bum Hong, MD ${ }^{2,5}$, Soo-Jong Hong, MD ${ }^{2,6}$ \\ 'Department of Psychiatry, University of Ulsan College of Medicine, Asan Medical Center, Seoul, Korea \\ ${ }^{2}$ Environmental Health Center, Asan Medical Center, Seoul, Korea \\ ${ }^{3}$ Department of Psychiatry, Veterans Health Service Medical Center, Seoul, Korea \\ ${ }^{4}$ Department of Psychiatry, Ulsan University Hospital, University of Ulsan College of Medicine, Ulsan, Korea \\ ${ }^{5}$ Department of Pulmonology and Critical Care Medicine, Asan Medical Center, University of Ulsan College of Medecine, Seoul, Korea \\ ${ }^{6}$ Department of Pediatrics, Childhood Asthma Atopy Center, Asan Medical Center, University of Ulsan College of Medicine, Seoul, Korea
}

\author{
Received: March 28, 2018 \\ Revised: April 30, 2018 \\ Accepted: April 30, 2018 \\ Correspondence \\ Seockhoon Chung, MD \\ Department of Psychiatry, University of Ulsan \\ College of Medicine, Asan Medical Center, \\ 88 Olympic-ro 43-gil, Songpa-gu, \\ Seoul 05505, Korea \\ Tel +82-2-3010-3411 \\ Fax +82-2-485-8381 \\ E-mailschung@amc.seoul.kr \\ ORCID \\ Seockhoon Chung \\ https://orcid.org/0000-0002-9798-3642 \\ Suk-Hoon Kang \\ https://orcid.org/0000-0001-7029-2289 \\ Kukju Kweon \\ https://orcid.org/0000-0003-1367-5704 \\ Soyoung Youn \\ https://orcid.org/0000-0003-4983-4017 \\ Hyang Soon Kang \\ https://orcid.org/0000-0001-6120-9973 \\ Sang-Bum Hong \\ https://orcid.org/0000-0003-2737-7695 \\ Soo-Jong Hong \\ https://orcid.org/0000-0003-1409-2113
}

Background and Objective In South Korea, numerous people have died of lung injury from humidifier disinfectant. The objective of this study was to explore the association between cognitive emotion regulation strategies for victims of humidifier disinfectant accidents in Korea and their insomnia and other psychiatric problems.

Methods Among 196 subjects experiencing humidifier disinfectant-related interstitial pneumonitis, 40 subjects were assessed for their psychological states between June 2015 and May 2016. Their psychiatric symptoms were assessed using Insomnia Severity Index, Hospital Anxiety and Depression Scales, Patient Health Questionnaire-9, posttraumatic stress disorder Checklist for DSM-5, and Cognitive Emotion Regulation Questionnaire.

Results Subjects' adaptive cognitive emotion regulation strategies were not correlated with rating scale scores. However, total score of maladaptive cognitive emotion regulation strategy was significantly correlated with all rating scale scores (all $\mathrm{p}<0.01$ ). Among maladaptive strategies, rumination and catastrophizing strategies were significantly correlated with severity of insomnia and other psychiatric symptoms.

Conclusions There was an association between victims' maladaptive coping strategies and insomnia or other psychiatric symptoms. Thus, managing their coping strategies is necessary to help them survive in their current environment.

Sleep Med Res 2018;9(1):26-31

Key Words Humidifiers, Disinfectants, Adaptation, Insomnia.

\section{INTRODUCTION}

In 1994, the Korea Oil Corporation (present SK Chemical) developed the world's first humidifier disinfectant product and South Korea became the world's first country to use humidifier disinfectant as a necessity for life. In 2009, the pandemic of H1N1 influenza in South Korea increased interest in indoor hygiene and the use of humidifier disinfectant. By 2011, when the use of the humidifier disinfectant ceased, more than 20 products had been introduced and $18.1 \%$ of people had used humidifier disinfectant in South Korea [1]. After 2006, acute interstitial lung diseases in children and peripartum women showing high morbidity and mortality have been reported [2-4]. In August 2011, the Korean Centers for Disease Control and Prevention (KCDC) under the Ministry of Health and Welfare announced that odds ratio of interstitial lung injury associated with humidifier disinfectant usage was 47.3 (95\% confidence inter- 
val: 6.0-369.7). Thus, KCDC ordered a product recall in November 2011 (Korea Centers for Disease Control and Prevention, 2011). In December 2012, a Lung Injury Investigation Committee was launched. In July 2013, official investigation and damage survey of humidifier disinfectants were started. The first (from July 2013 to April 2014) and the second (from July 2014 to April 2015) investigation surveys have concluded while the third survey (from September 2015) is still undergoing. The fourth investigation (from April 2016) is currently accepting applicants.

Victims of humidifier disinfectants suffer from physical disabilities and psychiatric symptoms such as insomnia, depression, and post-traumatic stress disorder (PTSD). Unfortunately, psychiatric evaluation of victims was not conducted at the time when we recognized that victims physical disease was due to humidifier disinfectant. We began psychiatric assessment for victims from 2014. Therefore, the status of their psychiatric status might be different from that of victims of other disasters [5]. In addition, victims of humidifier disinfectants experienced complex traumatic events, including toxic chemical exposure, life-threatening accidents, and unexpected death of loved ones simultaneously. They did not recognize that humidifier disinfectants were toxic agents. Many individuals used humidifier disinfectants to keep a healthy and humid condition. Exposure to humidifier disinfectants induced various diseases as well as lung injury, even leading to death of their loved ones.

Encountering traumatic events such as accidents, natural disasters, war, terror, cancer diagnosis, and other severe illnesses activates certain coping processes that can protect individuals from being overwhelmed and help them adjust to the situation. Numerous studies have focused on coping abilities as mediating factors or predictors of patients' distress severity and psychiatric outcomes under stressful experiences [6,7]. Especially, cognitive component plays a critical role in the coping process by affecting the way a person perceives and interprets adverse life events. Cognitive emotion regulation strategies can be adaptive or maladaptive depending on individuals $[8,9]$. Maladaptive emotion regulation strategies have been associated with more distress symptoms or onset of psychopathologies such as depressive disorder and PTSD while adaptive strategies have been related to fewer symptoms and ability to overcome stressful situations $[8,10,11]$.

Struggling with a fatal disease of unknown etiology and losing loved ones to the disease are very traumatic and stressful events. However, what makes victims even more distressed and angry over time is realizing the fact that the immediate cause was the specific humidifier disinfectant that they had themselves chosen. Pro-active support for treatment and compensation must take precedence to help these victims. As part of these efforts, it is important to try to understand their emotional distress and explore if there are any factors associated with symptom severity or disease onset. Particularly, specific cognitive emotion regulation strategy per se can be targeted with psychiatric intervention if it is revealed as a possible bridge between external stressor and psychopathological outcome [12,13]. The aim of this study was to explore the association between cognitive emotion regulation strategies of victims of humidifier disinfectants in Korea and their insomnia and other psychiatric problems.

\section{METHODS}

This study was approved by the Institutional Review Board of Asan Medical Center (2014-0840). Among 196 subjects who were experiencing humidifier disinfectant-associated lung injury (HDLI) confirmed by the Environmental Health Center of Asan Medical Center, 40 subjects who gave informed consent to participate in this study visited the psychiatric clinic of Asan Medical Center to assess their psychological states between June 2015 and May 2016. Their severity of insomnia was assessed using Insomnia Severity Index (ISI) [14]. Their anxiety and depressive symptoms were assessed using Hospital Anxiety and Depression Scales (HADS) [15] and Patient Health Questionnaire-9 (PHQ-9) [16]. Post-traumatic stress was evaluated using PTSD Checklist for DSM-5 (PCL-5) [17]. Coping strategies were assessed using Cognitive Emotion Regulation Questionnaire (CERQ) [18].

The ISI is a 7-item tool for assessing the severity of insomnia. Cutoff of ISI for insomnia was set at 8 [19]. The HADS was designed to detect states of depression, anxiety, and emotional stress using seven depression items and seven anxiety items. The PHQ-9 is a 9-item tool for screening and diagnosis of depression related to DSM-IV. The cutoff of PHQ-9 for probable depression was set at 10 [20]. The PCL-5 is a self-report measure of DSM-5 PTSD symptom criteria [21]. Cutoff of PCL-5 for probable PTSD was set at 38 [17]. The CERQ is a 36-item questionnaire to measure subjects' cognitive emotion regulation strategy. Adaptive strategies (putting into perspective, refocus on planning, positive refocusing, acceptance, and positive reappraisal) and maladaptive strategies (self-blame, other-blame, rumination, and catastrophizing) can be assessed using this scale.

\section{Statistical Analysis}

Statistical analyses were performed using SPSS version 21.0 (IBM Corp., Armonk, NY, USA). Student's t-test for continuous variables and chi-square test for categorical variables were performed. Spearman correlation rho was estimated to explore the association between cognitive emotion regulation strategies and psychiatric symptoms severity. The level of significance was defined at $\mathrm{p}<0.05$ for two-tailed tests of all analyses. 


\section{RESULTS}

Forty subjects (13 males and 27 females) with mean age of $40.3 \pm 6.3$ years (range, 28-62 years) were included in this study (Table 1). The likelihood of their HDLI was classified by a referral to archetypal confirmed cases as follows: definite $(n=16)$, probable $(n=10)$, possible $(n=10)$, and unlikely $(n=4)$ according to the classification criteria of the Health Environmental Center of Asan Medical Center [22]. Three subjects underwent lung transplantation after lung injury. Thirteen subjects experienced their partners or kids' death from humidifier disinfectant use.

There was no significant difference in ISI, HADS, PHQ-9, PCL-5, or CERQ score between men and women. There was no

Table 1. Demographic and clinical characteristics of subjects

\begin{tabular}{|c|c|}
\hline & Values \\
\hline Age (years old) & $40.3 \pm 6.3(28-62)$ \\
\hline $\operatorname{Sex}(M / F)$ & $13 / 27$ \\
\hline \multicolumn{2}{|c|}{ The likelihood of interstitial lung injury diagnosis (n) } \\
\hline Definite/probable/possible/unlikely & $16 / 10 / 10 / 4$ \\
\hline Lung transplantation (subject) & 3 \\
\hline \multicolumn{2}{|l|}{ Stressful events related with family member (n) } \\
\hline Death of family member (partner) & 2 \\
\hline Death of family member (child) & 10 \\
\hline Lung transplantation (family member) & 2 \\
\hline Likelihood of diagnosis of family member & 17 \\
\hline None of above & 16 \\
\hline \multicolumn{2}{|l|}{ Rating scales } \\
\hline ISI score & $11.6 \pm 5.4$ \\
\hline PHQ-9 score & $11.4 \pm 7.4$ \\
\hline HADS depression score & $11.5 \pm 3.1$ \\
\hline HADS anxiety score & $9.8 \pm 3.2$ \\
\hline PCL-5 score & $39.9 \pm 18.2$ \\
\hline Adaptive cognitive emotion regulation & $25.9 \pm 8.3$ \\
\hline Putting into perspective & $4.4 \pm 2.6$ \\
\hline Refocus on planning & $6.0 \pm 2.2$ \\
\hline Positive refocusing & $4.3 \pm 1.5$ \\
\hline Acceptance & $6.0 \pm 2.2$ \\
\hline Positive reappraisal & $5.3 \pm 2.5$ \\
\hline Maladaptive cognitive emotion regulation & $22.8 \pm 6.3$ \\
\hline Self-blame & $5.4 \pm 2.6$ \\
\hline Other-blame & $5.7 \pm 2.5$ \\
\hline Rumination & $5.6 \pm 2.1$ \\
\hline Catastrophizing & $6.0 \pm 2.6$ \\
\hline
\end{tabular}

Mean \pm SD.

ISI: Insomnia Severity Index, PHQ-9: Patient Health Questionnaire-9, HADS: Hospital Anxiety and Depression Scale, PCL-5: posttraumatic stress disorder checklist for DSM-5. significant difference in these scores among subjects grouped based on likelihood of HDLI (definite, possible, probable, or unlikely) either. No significant difference was found between subjects who did experience family members' death and those who did not. Scores of maladaptive cognitive emotion regulation strategies were significantly higher in subjects who were considered to have insomnia, depression, or posttraumatic stress (Table 2). However, scores of adaptive regulation strategies were not significantly higher in subjects who were considered to not have psychiatric symptoms except positive refocusing strategies.

Subjects' adaptive cognitive emotion regulation strategies were not correlated with rating scale scores in this study (Table 3 ). However, total score of maladaptive cognitive emotion regulation strategy was significantly correlated with all rating scale scores (all $\mathrm{p}<0.01$ ). Among maladaptive strategies, rumination and catastrophizing strategies were significantly correlated with all rating scale scores. In addition, other-blame strategy was correlated with PCL-5 and HADS-depression scores.

\section{DISCUSSION}

In this study, maladaptive cognitive emotion regulation strategy was associated with subjects' insomnia and other psychiatric symptoms such as depression, anxiety, and posttraumatic stress symptoms. However, no negative association was observed between adaptive cognitive emotion regulation strategies and psychiatric symptoms. Victims of humidifier disinfectants had psychiatric symptoms due to sudden lung injury or deaths of loved ones. However, delayed reaction by the government and manufacturers led to anger and frustration among victims. During this 5-year period of long-term frustration, some families were broken and some victims should have undergone lung transplantation. Victims blamed themselves for buying and using the humidifier disinfectant and letting their family members die (self-blame). They had anger toward the government and manufacturers (other-blame). They experienced repetitive thinking about the cause of lung injury and death of family members (rumination). They had the worst resultant frustration over delayed reaction by the government/manufacturers (catastrophizing). These might be associated with their psychiatric symptoms.

Studies on the association between individual cognitive emotion regulation strategy and psychological outcome under stressful life event have increased over recent years. Among nine cognitive strategies, rumination or catastrophizing was consistently related to more negative effect or higher depressive symptom. On the contrary, some adaptive strategies such as positive refocusing, refocusing on planning, and putting into perspective are related to lower depressive symptoms [23-25]. Very little is known about PTSD symptoms mediated by cognitive emotion regulation after traumatic events. However, findings are not dif- 
Table 2. Cognitive emotion regulation strategy of subjects who were considered having depression, PTSD, and insomnia

\begin{tabular}{|c|c|c|c|c|c|c|}
\hline & $\begin{array}{c}\text { ISI < 8 } \\
(\mathrm{n}=13)\end{array}$ & $\begin{array}{c}\text { ISI } \geq 8 \\
(\mathrm{n}=27)\end{array}$ & $\begin{array}{c}\text { PHQ-9 }<10 \\
(n=23)\end{array}$ & $\begin{array}{c}\text { PHQ-9 } \geq 10 \\
(\mathrm{n}=17)\end{array}$ & $\begin{array}{c}\text { PCL-5 <38 } \\
(\mathrm{n}=23)\end{array}$ & $\begin{array}{c}\text { PCL-5 } \geq 38 \\
(\mathrm{n}=17)\end{array}$ \\
\hline Age & $42.3 \pm 7.3$ & $42.1 \pm 10.8$ & $42.5 \pm 10.7$ & $41.6 \pm 8.5$ & $43.3 \pm 10.5$ & $40.6 \pm 8.7$ \\
\hline Adaptive cognitive emotion regulation & $28.0 \pm 6.9$ & $26.7 \pm 7.5$ & $27.2 \pm 6.7$ & $27.1 \pm 8.1$ & $27.3 \pm 7.6$ & $26.9 \pm 7.0$ \\
\hline Putting into perspective & $4.5 \pm 2.5$ & $4.4 \pm 2.3$ & $4.3 \pm 2.2$ & $4.8 \pm 2.6$ & $4.7 \pm 2.2$ & $4.2 \pm 2.5$ \\
\hline Refocus on planning & $6.0 \pm 2.0$ & $6.5 \pm 2.1$ & $6.1 \pm 1.8$ & $6.6 \pm 2.4$ & $6.1 \pm 2.1$ & $6.6 \pm 2.0$ \\
\hline Positive refocusing & $5.0 \pm 2.4$ & $4.7 \pm 1.9$ & $5.4 \pm 2.1$ & $4.1 \pm 1.7^{*}$ & $4.9 \pm 2.2$ & $4.7 \pm 1.9$ \\
\hline Acceptance & $6.2 \pm 2.0$ & $6.0 \pm 2.2$ & $5.8 \pm 2.0$ & $6.4 \pm 2.3$ & $5.9 \pm 1.8$ & $6.2 \pm 2.5$ \\
\hline Positive reappraisal & $6.3 \pm 1.6$ & $5.1 \pm 2.4$ & $5.7 \pm 2.0$ & $5.3 \pm 2.5$ & $5.7 \pm 2.2$ & $5.2 \pm 2.2$ \\
\hline Maladaptive cognitive emotion regulation & $14.6 \pm 4.0$ & $23.4 \pm 6.1^{\dagger}$ & $17.0 \pm 5.9$ & $25.5 \pm 4.8^{\dagger}$ & $16.3 \pm 4.6$ & $26.3 \pm 5.1^{\dagger}$ \\
\hline Self-blame & $3.7 \pm 1.8$ & $5.7 \pm 2.4^{\dagger}$ & $4.1 \pm 1.7$ & $6.3 \pm 2.6^{\dagger}$ & $4.1 \pm 2.1$ & $6.3 \pm 2.2^{\dagger}$ \\
\hline Other-blame & $4.8 \pm 1.0$ & $6.0 \pm 1.3^{\dagger}$ & $5.2 \pm 1.2$ & $6.1 \pm 1.4^{*}$ & $4.8 \pm 1.0$ & $6.5 \pm 1.2^{\dagger}$ \\
\hline Rumination & $3.2 \pm 1.4$ & $6.0 \pm 1.9^{\dagger}$ & $4.2 \pm 2.0$ & $6.4 \pm 1.7^{\dagger}$ & $4.1 \pm 1.7$ & $6.5 \pm 2.1^{\dagger}$ \\
\hline Catastrophizing & $3.4 \pm 1.9$ & $6.0 \pm 2.4^{\dagger}$ & $4.0 \pm 2.1$ & $6.8 \pm 2.4^{\dagger}$ & $3.8 \pm 1.9$ & $7.1 \pm 2.2^{\dagger}$ \\
\hline
\end{tabular}

${ }^{*} \mathrm{p}<0.05 .{ }^{\dagger} \mathrm{p}<0.01$.

ISI: Insomnia Severity Index, PHQ-9: Patient Health Questionnaire-9, PCL-5: PTSD Checklist for DSM-5, PTSD: posttraumatic stress disorder.

Table 3. Cognitive emotion regulation strategies and psychiatric symptoms

\begin{tabular}{|c|c|c|c|c|c|}
\hline & \multirow{2}{*}{ ISI } & \multirow{2}{*}{ PHQ-9 } & \multicolumn{2}{|c|}{ HADS } & \multirow{2}{*}{ PCL-5 } \\
\hline & & & Anxiety & Depression & \\
\hline Age & -0.02 & 0.13 & 0.07 & 0.35 & 0.06 \\
\hline Adaptive cognitive emotion regulation & 0.07 & -0.05 & -0.05 & -0.27 & -0.04 \\
\hline Putting into perspective & 0.10 & 0.08 & 0.05 & -0.15 & -0.05 \\
\hline Refocus on planning & 0.19 & -0.02 & 0.02 & -0.21 & -0.01 \\
\hline Positive refocusing & -0.07 & -0.22 & -0.04 & 0.02 & 0.12 \\
\hline Acceptance & 0.04 & -0.13 & -0.14 & -0.30 & -0.13 \\
\hline Positive reappraisal & -0.03 & 0.002 & -0.09 & -0.30 & -0.03 \\
\hline Maladaptive cognitive emotion regulation & $0.62^{\dagger}$ & $0.59^{\dagger}$ & $0.70^{\dagger}$ & $0.60^{\dagger}$ & $0.83^{\dagger}$ \\
\hline Self-blame & 0.35 & 0.23 & 0.10 & 0.06 & 0.28 \\
\hline Other-blame & 0.15 & 0.24 & 0.27 & $0.50^{*}$ & $0.43^{*}$ \\
\hline Rumination & $0.69^{\dagger}$ & $0.64^{\dagger}$ & $0.73^{+}$ & $0.62^{\dagger}$ & $0.76^{\dagger}$ \\
\hline Catastrophizing & $0.45^{*}$ & $0.48^{*}$ & $0.75^{\dagger}$ & $0.43^{*}$ & $0.72^{\dagger}$ \\
\hline
\end{tabular}

${ }^{*} \mathrm{p}<0.05 .{ }^{\dagger} \mathrm{p}<0.01$.

ISI: Insomnia Severity Index, PHQ-9: Patient Health Questionnaire-9, HADS: Hospital Anxiety and Depression Scale, PCL-5: posttraumatic stress disorder checklist for DSM-5.

ferent from those for depression. More maladaptive strategies such as rumination and catastrophizing are frequently reported as predictors of developing PTSD or more severe symptoms whereas more adaptive strategies are related to lower symptoms or even posttraumatic growth $[7,11,26]$. Our findings of significant correlations between maladaptive strategies and insomnia, depression, anxiety, and posttraumatic symptoms are consistent with findings from previous studies. One distinguishing pattern observed in our results was that adaptive strategies were not significantly associated with reduced distress symptoms. Another remarkable feature was that other-blame strategy was associated with higher level of distress symptoms, unlike earlier studies. These results might reflect the unique situation that psychiatric examinations for victims were launched after the specific humidifier disinfectant had been shown as a cause of long-term mysterious disease. Humidifier disinfectant as a daily necessity that causes a disorder is an unusual disaster. Many victims were among the most active population of healthcare such as peripartum mothers. They purchased these humidifier disinfectants and used them every day in order to protect themselves and their families. The belief that they personally led to this disaster caused them to have serious sense of guilt and regret. Moreover, the Korean government and manufacturers showed delayed reactions to voices of victims and various civil-society 
organizations. Psychological support should be given to victims for their depression and posttraumatic stress symptoms. Their maladaptive coping strategies driven from the disaster should be properly managed to reduce their psychiatric problems.

We did not estimate the proportion of subjects' psychiatric diagnosis in this study. A psychiatric evaluation was not conducted at the time when the humidifier disinfectant was first recognized as a cause of the mysterious lung disease. When we began psychiatric evaluation for victims, their psychiatric symptoms were somewhat different from those of other previous disasters. In general, researchers categorize disasters into three types: 1) natural disasters (e.g., earthquake); 2) non-intentional, human-made technological disasters (e.g., the nuclear accident at Chernobyl); and 3) intentional human-made disasters (e.g. such as terrorism) [13,27]. Humidifier disinfectant belongs to the non-intentional, technological disaster because it is a toxic chemical, like the itai-itai disease in Japan and Love Canal disaster in the United States. In these environmental disasters, a toxic environmental chemical that was accumulated for a long period was causing physical and mental health problems. After a considerable time, the cause of the disaster was then discovered. Therefore, many victims suffered from a disease of unknown origin. They did not receive proper treatment or compensation for a long time. Some researchers have reported that human-made technological disasters tend to have higher mental impact than natural disasters $[28,29]$. We were unaware and unprepared to evaluate these victims, support them psychologically, and manage their coping strategy at the beginning. Henceforth, we should design a system to support these victims [22].

The small sample size is one of the limitations of this study. About five years have passed after the humidifier disinfectant disaster, victims seem to have adjusted to their situation. In addition, since subjects are living in various cities in South Korea distant from Seoul where the Environment Health Center of Asan Medical Center is located, it is difficult for them to visit for follow-up checks of their psychological states. Second, results in this study did not reveal the causal relationship between victims' coping strategies and their psychiatric symptoms because we only performed a correlation analysis, not a prospective follow-up study. One should be cautious when interpreting results of this study to suggest that victims' maladaptive coping strategies are the ones that have influenced their severe posttraumatic stress symptoms. Victims suffer from physical and psychological stress. They struggle to keep their mind stable. Their coping strategies to adjust to their current environment should be respected.

In conclusion, we observed associations between humidifier disinfectant disaster victims' maladaptive coping strategies resulting from severe stressful events and delayed reaction of responsible manufacturers, their insomnia, depression, and posttraumatic stress. Managing their coping strategies is necessary to help them survive in their current environment.

\section{Acknowledgments}

This study was supported by the Environmental Health Research Center Project funded by the Ministry of Environment, Republic of Korea.

\section{Conflicts of Interest}

The authors have no financial conflicts of interest.

\section{Authors' Contribution}

Conceptualization: Hong SJ, Chung S. Data curation: Chung S, Kang HS, Hong SJ. Formal analysis: Chung S, Kweon KJ, Kang SH, Youn S. Investigation: Chung S, Youn S, Kweon KJ, Kang SH. Methodology: Kang SH, Chung S. Project administration: Chung S. Resources: Hong SJ, Hong SB, Kang HS. Software: Chung S. Supervision: Chung S, Hong SB. Validation: Chung S, Youn S, Kang SH, Hong SB. Writing_original draft: Chung S, Kweon KJ, Kang SH, Youn S. Writing_-review \& editing: Hong SJ, Hong SB.

\section{REFERENCES}

1. Jeon BH, Park YJ. Frequency of humidifier and humidifier disinfectant usage in gyeonggi provine. Environ Health Toxicol 2012;27:e2012002.

2. Lee E, Seo JH, Kim HY, Yu J, Jhang WK, Park SJ, et al. Toxic inhalational injury-associated interstitial lung disease in children. J Korean Med Sci 2013;28:915-23.

3. Kim BJ, Kim HA, Song YH, Yu JH, Kim SG, Park SJ, et al. Nationwide surveillance of acute interstital pneumonia in Korea. Korean J Pediatr 2009;52:324-9.

4. Cheon CK, Jin HS, Kang EK, Kim HB, Kim BJ, Yu JH, et al. Epidemic acute interstitial pneumonia in children occurred during the early 2006s. Korean J Pediatr 2008;51:383-90.

5. Oe M, Fujii S, Maeda M, Nagai M, Harigane M, Miura I, et al. Threeyear trend survey of psychological distress, post-traumatic stress, and problem drinking among residents in the evacuation zone after the Fukushima Daiichi Nuclear Power Plant accident [The Fukushima Health Management Survey]. Psychiatry Clin Neurosci 2016;70:245-52.

6. Bussell VA, Naus MJ. A longitudinal investigation of coping and posttraumatic growth in breast cancer survivors. J Psychosoc Oncol 2010;28: 61-78.

7. Jacobsen PB, Sadler IJ, Booth-Jones M, Soety E, Weitzner MA, Fields KK. Predictors of posttraumatic stress disorder symptomatology following bone marrow transplantation for cancer. J Consult Clin Psychol 2002;70:235-40

8. Garnefski N, Kraaij V, Spinhoven P. Negative life events, cognitive emotion regulation and emotional problems. Personality and Individual Differences 2001;30:1311-27.

9. Schroevers M, Kraaij V, Garnefski N. Goal diturbance, cognitive coping strategies, and psychological adjustment to different types of stressful life event. Personality and Individual Differences 2007;43:413-23.

10. Gross JJ, John OP. Individual differences in two emotion regulation processes: implications for affect, relationships, and well-being. J Pers Soc Psychol 2003;85:348-62.

11. Jenness JL, Jager-Hyman S, Heleniak C, Beck AT, Sheridan MA, McLaughlin KA. Catastrophizing, rumination, and reappraisal prospectively predict adolescent PTSD symptom onset following a terrorist attack. Depress Anxiety 2016;33:1039-47.

12. Cloitre M, Stovall-McClough KC, Nooner K, Zorbas P, Cherry S, Jackson CL, et al. Treatment for PTSD related to childhood abuse: a randomized controlled trial. Am J Psychiatry 2010;167:915-24.

13. Adler AD, Strunk DR, Fazio RH. What changes in cognitive therapy for depression? An examination of cognitive therapy skills and maladaptive beliefs. Behav Ther 2015;46:96-109.

14. Cho YW, Song ML, Morin CM. Validation of a Korean version of the insomnia severity index. J Clin Neurol 2014;10:210-5.

15. Oh SM, Min KJ, Park DB. A study on the standardization of the hospital anxiety and depression scale for Koreans: a comparison of normal, depressed and anxious groups. J Korean Neuropsychiatr Assoc 1999;38: 
289-96.

16. An JY, Seo ER, Lim KH, Shin JH, Kim JB. Standardization of the Korean version of screening tool for depression (Patient Health Questionnaire-9, PHQ-9). J Korean Soc Biol Ther Psychiatry 2013;19:47-56.

17. Weathers FW, Litz BT, Keane TM, Palmieri PA, Marx BP, Schnurr PP. The PTSD Checklist for DSM-5 (PCL-5) [updated 2013; cited 2018 Apr 10]; Available from: https://www.ptsd.va.gov/professional/assessment/adult-sr/ptsd-checklist.asp.

18. Ahn HN, Lee NB, Joo HS. Validation of the cognitive emotion regulation questionnaire in a Korea population. Korean J Counseling 2013;14: 1773-94.

19. Morin CM, Belleville G, Bélanger L, Ivers H. The Insomnia Severity Index: psychometric indicators to detect insomnia cases and evaluate treatment response. Sleep 2011;34:601-8.

20. Kroenke K, Spitzer RL, Williams JB. The PHQ-9: validity of a brief depression severity measure. J Gen Intern Med 2001;16:606-13.

21. Blevins CA, Weathers FW, Davis MT, Witte TK, Domino JL. The Posttraumatic Stress Disorder Checklist for DSM-5 (PCL-5): Development and Initial Psychometric Evaluation. J Trauma Stress 2015;28:489-98.

22. Choi JE, Hong SB, Do KH, Kim HJ, Chung S, Lee E, et al. Humidifier disinfectant lung injury, how do we approach the issues? Environ Health Toxicol 2016;31:e2016019.
23. Garnefski N, Kraaij V, Schroevers MJ, Aarnink J, van der Heijden DJ, van Es SM, et al. Cognitive coping and goal adjustment after first-time myocardial infarction: relationships with symptoms of depression. Behav Med 2009;35:79-86.

24. Schroevers M, Kraaij V, Garnefski N. How do cancer patients manage unattainable personal goals and regulate their emotions? Br J Health Psychol 2008;13:551-62.

25. Stikkelbroek Y, Bodden DH, Kleinjan M, Reijnders M, van Baar AL. Adolescent depression and negative life events, the mediating role of cognitive emotion regulation. PLoS One 2016;11:e0161062.

26. Hussain D, Bhushan B. Posttraumatic stress and growth among Tibetan refugees: the mediating role of cognitive-emotional regulation strategies. J Clin Psychol 2011;67:720-35.

27. Pietrzak RH, Tracy M, Galea S, Kilpatrick DG, Ruggiero KJ, Hamblen $\mathrm{JL}$, et al. Resilience in the face of disaster: prevalence and longitudinal course of mental disorders following hurricane Ike. PLoS One 2012;7: e38964.

28. Galea S, Nandi A, Vlahov D. The epidemiology of post-traumatic stress disorder after disasters. Epidemiol Rev 2005;27:78-91.

29. Norris FH, Friedman MJ, Watson PJ, Byrne CM, Diaz E, Kaniasty K. 60,000 disaster victims speak: Part I. An empirical review of the empirical literature, 1981-2001. Psychiatry 2002;65:207-39. 